\title{
Comparisons of high-risk cervical HPV infections in Caribbean and US populations
}

\author{
Camille C Ragin*1,2,8, Angela Watt ${ }^{3}$, Nina Markovic ${ }^{1}$, Clareann H Bunker ${ }^{1,7}$, \\ Robert P Edwards ${ }^{4}$, Stacy Eckstein ${ }^{1,2}$, Horace Fletcher ${ }^{3}$, David Garwood ${ }^{3}$, \\ Susanne M Gollin ${ }^{5}$, Maria Jackson ${ }^{3}$, Alan L Patrick ${ }^{1,7}$, M Smikle ${ }^{3}$, \\ Emanuela Taioli1,2,8, Victor W Wheeler ${ }^{1,6,7}$, Jacque B Wilson ${ }^{6}$, N Younger ${ }^{3}$ \\ and Norma McFarlane-Anderson ${ }^{3}$
}

\begin{abstract}
Address: ${ }^{1}$ Department of Epidemiology, University of Pittsburgh Graduate School of Public Health, Pittsburgh, USA, ${ }^{2}$ Division of Cancer Prevention and Population Science, University of Pittsburgh Cancer Institute, Pittsburgh, USA, ${ }^{3}$ Faculty of Medical Sciences, University of the West Indies, Kingston, Jamaica, ${ }^{4}$ Division of Gynecologic Oncology, University of Pittsburgh Cancer Institute, Pittsburgh, USA, ${ }^{5}$ Department of Human Genetics, University of Pittsburgh Graduate School of Public Health and University of Pittsburgh Cancer Institute, Pittsburgh, USA, ${ }^{6}$ Tobago Branch, Trinidad and Tobago Cancer Society, Scarborough, Tobago, Trinidad \& Tobago, ${ }^{7}$ Tobago Health Studies Office, Scarborough, Tobago, Trinidad \& Tobago and ${ }^{8}$ Department of Epidemiology and Biostatistics, Downstate School of Public Health, State University of New York, USA

Email: Camille C Ragin* - Camille.Ragin@downstate.edu; Angela Watt - wattangela@yahoo.com; Nina Markovic - ninam@dental.pitt.edu; Clareann H Bunker - bunkerc@pitt.edu; Robert P Edwards - redwards@mail.magee.edu; Stacy Eckstein - ecksteins@upmc.edu; Horace Fletcher - horace.fletcher@uwimona.edu.jm; David Garwood - doctorgarwood@yahoo.com; Susanne M Gollin - gollin@pitt.edu; Maria Jackson - maria.jackson@uwimona.edu.jm; Alan L Patrick - apatrick_4127@yahoo.co.uk; M Smikle - monica.smikle@uwimona.edu.jm; Emanuela Taioli - emanuela.taioli@downstate.edu ; VictorWWheeler - victorwheeler74@gmail.com; Jacque B Wilson - ragincc@upmc.edu; N Younger - novie.younger@uwimona.edu.jm; Norma McFarlane-Anderson - norma.mcfarlaneanderson@uwimona.edu.jm

* Corresponding author
\end{abstract}

from Second Annual International African-Caribbean Cancer Consortium Conference Miami, FL, USA. 12-13 May 2008

Published: 10 February 2009

Infectious Agents and Cancer 2009, 4(Suppl I):S9 doi:I0.1 I86/I750-9378-4-SI-S9

This article is available from: http://www.infectagentscancer.com/content/4/SI/S9

(c) 2009 Ragin et al; licensee BioMed Central Ltd.

This is an open access article distributed under the terms of the Creative Commons Attribution License (http://creativecommons.org/licenses/by/2.0), which permits unrestricted use, distribution, and reproduction in any medium, provided the original work is properly cited.

\begin{abstract}
Background: Disparities in cervical cancer incidence and mortality rates exist among women of African ancestry (African-American, African-Caribbean and African). Persistent cervical infection with Human papillomavirus (HPV) is associated with cervical dysplasia and if untreated, could potentially progress to invasive cervical cancer. Very few studies have been conducted to examine the true prevalence of HPV infection in this population. Comparisons of cervical HPV infection and the type-specific distribution of HPV were performed between cancer-free Caribbean and US women.
\end{abstract}

Results: The Caribbean population consisted of 212 women from Tobago and 99 women from Jamaica. The US population tested, consisted of 82 women from Pittsburgh. The majority of the US subjects was Caucasian, 74\% (6I/82) while I2\% (10/82) and 13\% (II/82) were African-American or other ethnic groups, respectively. The age-adjusted prevalence of any HPV infection among women from Tobago was $35 \%$, while for Jamaica, it was $81 \%(p<0.0001)$. The age-adjusted prevalence of HPV infection for Caribbean subjects was not statistically significantly different from the US (any 
HPV: $47 \%$ vs. $39 \%, p>0.1$; high-risk HPVs: $27 \%$ vs. $25 \%, p>0.1$ ); no difference was observed between US-Blacks and Jamaicans (any HPV: $92 \%$ vs. $81 \%, p>0.1$; high-risk HPV: $50 \%$ vs. $53 \%, p>$ 0.I). However, US-Whites had a lower age-adjusted prevalence of HPV infections compared to Jamaican subjects (any HPV: $29 \%$ vs. $81 \%$, p < 0.000I; high-risk HPV: $20 \%$ vs. 53\%, p < 0.00I). Subjects from Jamaica, Tobago, and US-Blacks had a higher proportion of high-risk HPV infections (Tobago: $20 \%$, Jamaica: 58\%, US-Blacks: $40 \%$ ) compared to US-Whites (I5\%). Similar observations were made for the presence of infections with multiple high-risk HPV types (Tobago: I2\%, Jamaica: 43\%, US-Blacks: $30 \%$, US-Whites: $8 \%$ ). Although we observed similar prevalence of HPVI6 infections among Caribbean and US-White women, there was a distinct distribution of high-risk HPV types when comparisons were made between the ethnic groups.

Conclusion: The higher prevalence of cervical HPV infections and multiple high-risk infections in Caribbean and US-Black women may contribute to the high incidence and prevalence of cervical cancer in these populations. Evaluation of a larger sample size is currently ongoing to confirm the distinct distribution of HPV types between ethnic groups.

\section{Background}

Disparities in cervical cancer incidence and mortality rates exist among all women of African ancestry (African-American, African-Caribbean and African) [1,2]. The world standardized age-adjusted incidence and mortality rates per 100,000 for African-American women are 8.6 and 3.4, respectively vs. 6.7 and 1.7 for Caucasians in the United States (US) [1]. Furthermore, African and Caribbean countries have the top two highest incidence and mortality rates, above Asia, the Americas and Europe [2].

Almost all cases of invasive cancers of the cervix, most other anogenital tract cancers [3], and approximately 36\% of oropharyngeal cancers [4], are associated with HPV infection. In addition to persistent HPV infection with high-risk genotypes, access to screening as well as behaviors such as early age of sexual intercourse, multiple sex partners, and lifetime number of partners are risk factors associated with the development of cervical cancer. Although the HPV infection rate is high in the Caribbean [5], very few studies have been conducted to measure the true prevalence of HPV infection in this population. In addition, there are not enough data that describe the distribution of HPV types among cancer cases and healthy controls from the many islands throughout the Caribbean. Since the HPV vaccine specifically prevents cancers caused by HPV16 and 18, knowledge of the HPV type distribution in these populations is important in order to evaluate the impact of the current HPV vaccine on these at-risk populations.

We have previously reported the HPV type distribution in two cancer-free Caribbean populations, Jamaica [6] and Tobago [7]. In this study, we have compared the prevalence and genotype distribution of cervical HPV infections in these two Caribbean populations with that of US women.

\section{Methods \\ Study population}

The Caribbean populations consisted of 212 women from Tobago [6] and 99 women from Jamaica [7]. The US population consisted of 88 women from Pittsburgh. All of the subjects from the three geographic areas were recruited from the general population and none were pregnant. The women from Tobago were recruited between July and September 2004 by means of posters, flyers, public service announcements on television and radio, word of mouth, and a series of cancer information sessions conducted throughout the island. The Jamaican women were recruited during visits to a family practice in Western Jamaica between January 2003 and October 2006. All Jamaican participants were recruited consecutively to avoid selection bias. The US study population was enrolled from May 2007-Aug 2008 as part of a nested cross-sectional study of the Epidemiologic STudy of HEalth Risk (ESTHER) project, (an ongoing women's study at the University of Pittsburgh). The ESTHER project's sample recruitment methodology attempted to address some of the biases related to use of a sample of convenience. The targeted recruitment for ESTHER was based on age, level of education, and race/ethnicity population distributions. Recruitment strategies included attending women focused events, news items and advertisements in women-focused news sources, and limited respondent driven sampling.

All subjects from Jamaica and Tobago combined are referred to in this study as Caribbean. The majority of subjects were African-Caribbean, although in Tobago, there were 19 subjects who defined their ethnicity as East Indian. The self-reported ethnic groups in the US population were classified as White, Black or other ethnic groups. One subject did not define her ethnicity and was included in the other ethnic group category. 


\section{HPV testing}

Standardized protocols were implemented for sample collection, DNA extraction and HPV testing for all three subpopulations that were included in this analysis. A nurse or clinician collected cervical brush samples and the DNA was extracted from these samples using the Puregene DNA purification kit (Qiagen, Germantown, MD, USA). The HPV genotyping was performed on these samples using the Linear Array HPV Genotyping kit (Roche Diagnostics). All cervical samples were tested at the University of Pittsburgh. The assay involved amplification of samples by PCR using a master mix which contained biotin-labeled primers for the detection of the 37 most common HPV genotypes as well as the human beta-globin gene. The PCR products were chemically denatured and hybridized for $30 \mathrm{~min}$ at $53^{\circ} \mathrm{C}$ to linear array strips which contained specific and one cross-reactive oligonucleotide probe for the HPV genotypes as well as a high and low concentration of a beta-globin probe. The HPV genotypes were identified when visualized using a streptavidin-horseradish peroxidase conjugate and a substrate solution containing hydrogen peroxide and 3,3',5,5'-tetramethylbenzidine which yielded a blue precipitate at the positions where the hybridization occurred.

For six samples from the US population, beta-globin was not positive, which indicated either poor quality or low yield DNA samples. These samples were excluded. Therefore, HPV results were available for only 82 US samples. All of the samples from Jamaica were tested with the AMPLICOR HPV method [7] prior to testing with the Linear Array HPV Genotyping kit. Ten samples from the Jamaican population tested HPV-negative using our assay, possibly due to a lower sensitivity. Therefore, for our study, these samples were classified as HPV X.

The Linear Array protocol does not specifically detect HPV52. The cross-reactive probe in this assay detects HPV $33,35,52$ and 58 combined. According to the manufacturer's protocol, samples that are negative for HPV 33, 35, and 58 individually, but positive for the cross-reactive probe are classified as HPV 52-positive. Samples that are positive for HPV 33, 35, and/or 58 individually, as well as the cross-reactive probe have an uncertain HPV 52 status. For our study these samples were considered negative for HPV 52.

HPV-risk classification was based on the epidemiological classification of HPV types that are associated with cervical cancer [8]. Briefly there are fifteen high-risk HPV types: $16,18,31,33,35,39,45,51,52,56,58,59,68,73,82$; three probable high-risk HPV types: 26, 53, 66 and twelve low-risk HPV types: 6, 11, 40, 42, 43, 44, 54, 61, 70, 72, 81, CP6108. For this analysis, we combined probable high-risk HPV types and high-risk HPV types into a single group. The HPV types that do not fall into any of these aforementioned categories were classified as undetermined risk.

\section{Statistical analysis}

All statistical analyses were performed using STATA SE (version 10), (StataCorp LP, College Station, TX). Ageadjusted prevalence rates and confidence intervals were calculated using logistic regression estimates of infection with any HPV type or any high-risk HPV type, adjusted for age. Observations with missing values of age were dropped from the analysis before estimation. The chisquared test of proportions was used to calculate p-values for the unadjusted differences in proportions as well as, $\mathrm{p}$ values for the differences in adjusted proportions. Although age and age at first sexual intercourse were both normally distributed, we rejected the hypothesis of equal variances. Therefore, the comparisons of mean age and age at first sexual intercourse were performed using twosample t-tests on the equality of means adjusting for unequal variances.

Table I: Characteristics of the study population.

\begin{tabular}{|c|c|c|c|c|}
\hline & Tobago & Jamaica & US & Total \\
\hline Number of subjects & 212 & 99 & 82 & 393 \\
\hline Population source & GP & GP & GP & GP \\
\hline Age (years, mean $\pm S D$ ) & $4 I \pm 11.6$ & $\begin{array}{l}36 \pm 11.7 \\
(n=91)\end{array}$ & $53 \pm 9.0$ & $\begin{array}{l}42 \pm 12.7 \\
(n=391)\end{array}$ \\
\hline $\begin{array}{l}\text { Age, first sexual intercourse } \\
\text { (years, mean } \pm \text { SD) }\end{array}$ & $\begin{array}{l}18 \pm 3.5 \\
(n=191)\end{array}$ & $\begin{array}{l}17 \pm 2.8 \\
(n=95)\end{array}$ & $\begin{array}{l}19 \pm 3.8 \\
(n=80)\end{array}$ & $\begin{array}{l}18 \pm 3.5 \\
(n=366)\end{array}$ \\
\hline \multicolumn{5}{|l|}{ Number of sex partners $\mathrm{N}(\%)$} \\
\hline $\mathrm{I}-5$ & $153(79.7)$ & $72(74.2)$ & $48(60.8)$ & $273(74.2)$ \\
\hline $6-15$ & $39(20.3)$ & $20(20.6)$ & $24(30.4)$ & $83(22.6)$ \\
\hline $16+$ & $0(0.0)$ & $5(5.2)$ & $7(8.9)$ & $12(3.3)$ \\
\hline
\end{tabular}

GP = general population; SD = standard deviation; when there are subjects with missing data, the number of the subpopulation (n) used to calculate the overall means is indicated in each cell. 


\section{Results}

\section{Study populations}

Table 1 summarizes the characteristics of each subpopulation. The overall study population consisted of 393 subjects (mean age $42 \pm 12.7$ years) who were recruited from the general population. The Caribbean subjects consisted of 212 women from Tobago [6] (mean age: $41 \pm 11.6$ years). The 99 women from Jamaica [7] (mean age: $36 \pm$ 11.7 years) were the youngest population, while the US population, which consisted of 82 women (mean age: 53 \pm 9.0 years $)$ was the oldest $(\mathrm{p}<0.0001)$. The majority of subjects in the US population were White, $76 \%(67 / 88)$, while $11 \%(10 / 88)$ and $13 \%(11 / 88)$ were African-American or other ethnic groups, respectively.

The mean age at first sexual intercourse for each subpopulation ranged from 17 to 19 years old, with an overall mean of $18 \pm 3.5$ years. The age at first sexual intercourse for Jamaican women was statistically significantly younger than women from Tobago (Jamaica: $17 \pm 2.8$ years vs. Tobago: $18 \pm 3.5$ years, $\mathrm{p}=0.01)$ and US women (vs. US: $19 \pm 3.8$ years, $\mathrm{p}=0.0001$ ).

\section{Comparisons of cervical HPV prevalence between countries}

Thirty-five percent (75/212) of the women from Tobago, $84 \%$ (83/99) of the women from Jamaica and 32\% (26/ 82) of US women, tested positive for HPV infection of any HPV type. Table 2 summarizes the age-adjusted prevalence of HPV infections in our study population. Although the age-adjusted prevalence rate of any HPV infection was higher overall in the Caribbean $(47 \%)$, it was not significantly different from the United States (39\%, p = 0.281). Similar observations were made when only high-risk HPV infections were considered (Caribbean: $27 \%$, US 25\%, p = 0.758). The highest prevalence of high-risk HPV infections was observed in Jamaican women (age-adjusted prevalence $=53 \%$ ), while women from Tobago had a statistically significantly lower ageadjusted prevalence of high-risk HPV infections (18\%, p <
0.0001). Statistically significant differences were observed between the age-adjusted prevalence of high-risk HPV infections among US Whites (20\%) and Jamaican women $(\mathrm{p}=0.001)$. In contrast, there was no statistically significant difference in the prevalence of high-risk infections among US-Blacks (50\%) when compared to Jamaican subjects $(\mathrm{p}>0.1)$.

\section{Geographical distribution of high-risk HPV types and multiple high-risk HPV infections}

Figure 1 summarizes the HPV type distribution of highrisk HPV infections among all women infected with highrisk HPV types. In both Caribbean islands, HPV 45 (overall: 26\%, Tobago: $19 \%$ and Jamaica: 31\%) rather than HPV 16 (overall: 13\%, Tobago: $12 \%$ and Jamaica 14\%) or HPV 18 (overall: 14\%, Tobago: 5\% and Jamaica: 21\%) was the most common high-risk genotype detected. In contrast, US women had a different distribution of highrisk genotypes. HPV 33 infections were highest among the high-risk types in this population (overall: 29\%, USBlacks: 25\%, US-Whites: 22\%) rather than HPV 16 (overall: 7\%, US-Blacks: 0\%, US-Whites: 11\%) or HPV 18 (overall: 7\%, US-Blacks: 0\%, US-Whites: 11\%). Nevertheless, although not statistically significant, we observed a higher prevalence rate of HPV 16 and 18 infections among Caribbean subjects that were infected with high-risk HPV types when compared to the US women (HPV 16: 13\% vs. $7 \%, \mathrm{p}>0.1$ and HPV 18: $14 \%$ vs. $7 \%, \mathrm{p}>0.1$ ).

The proportion of high-risk HPV infections appears to be highest among women of African ancestry. Jamaican women had the highest proportion of high-risk HPV infections (58.6\%), then US-Black (40\%), Tobago (20.3\%) and US White (14.5\%) women, followed by women from the US-other group (10\%), (Table 3). Fifty percent of US-black women, $40.4 \%$ of Jamaican women, $23.1 \%$ of Tobago women, $16.1 \%$ of US-white $(40.4 \%)$ and $10 \%$ of women from the US-other group had single high-risk HPV infections. Similar observations were made for multiple high-risk HPV infections, US-whites and US-

Table 2: Prevalence of HPV infection by geographic location.

\begin{tabular}{|c|c|c|c|c|c|c|c|}
\hline Country & Test method & $\begin{array}{c}\text { Age-adjusted } \\
\text { prevalence any } \\
\mathrm{HPV}(\%), 95 \% \mathrm{Cl}\end{array}$ & p-value, Country & $\begin{array}{l}\text { P-value, Ethnic } \\
\text { group }\end{array}$ & $\begin{array}{l}\text { Age-Adjusted } \\
\text { prevalence high- } \\
\text { risk HPV (\%), } \\
95 \% \mathrm{Cl}\end{array}$ & P-value, Country & $\begin{array}{c}\text { P-value, Ethnic } \\
\text { group }\end{array}$ \\
\hline Caribbean & PCR & $47.1(41.3-53.0)$ & ref & & $27.4(22.3-33.3)$ & ref & \\
\hline Jamaica & & $80.5(70.5-87.8)$ & & ref & $52.7(41.4-63.6)$ & & ref \\
\hline Tobago & & $34.5(28.3-4 \mid .2)$ & & $<0.0001$ & $18.3(13.5-24.2)$ & & $<0.0001$ \\
\hline United States & PCR & $39.4(28.2-51.8)$ & 0.281 & & $25.3(15.5-38.4)$ & 0.758 & \\
\hline US-Blacks & & 91.8 (58.3-98.9) & & 0.368 & $49.7(21.4-78.2)$ & & 0.867 \\
\hline US-Whites & & $29.0(18.0-43.0)$ & & $<0.0001$ & $20.2(10.9-34.7)$ & & 0.001 \\
\hline US-Other & & $22.9(5.9-58.5)$ & & 0.002 & $16.0(2.3-61.0)$ & & 0.111 \\
\hline
\end{tabular}

$\mathrm{P}$-values for the differences in adjusted proportions. 


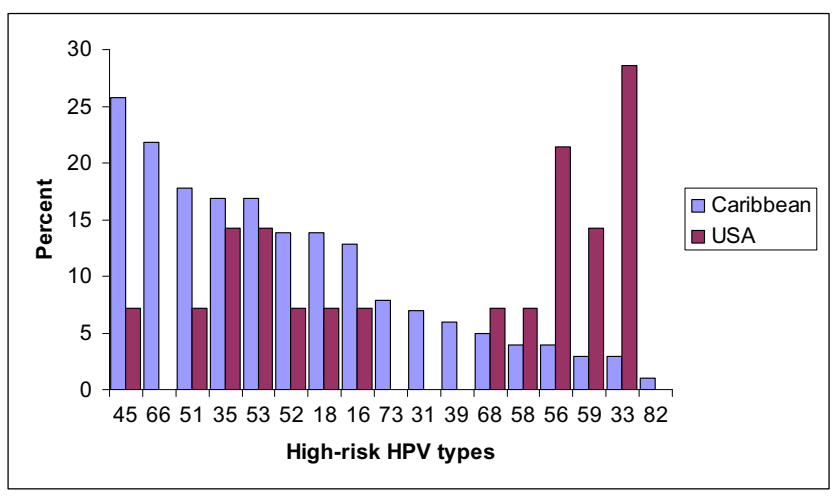

Figure I

Distribution of high-risk HPV types among Caribbean and US women with high-risk HPV infections.

other had lower proportions $(8.1 \%$ and $10 \%$, respectively). Higher proportions of multiple infections were observed among Jamaicans (43.4\%), US-blacks (30\%) and women from Tobago (12.3\%). In general, multiple high risk infections among Caribbean women ranged from 2-6 high-risk HPV types whereas no more than two high-risk HPV types were detected among US Blacks.

\section{Discussion}

This is the first study to report comparisons of the prevalence of cervical HPV infections and the specific HPV genotypes between cancer-free Caribbean and US women. We have shown that the age-adjusted prevalence rate of any HPV infection was higher in the Caribbean women (47\%) than in women from the United States (39\%), although the age-adjusted prevalence of high-risk HPV infections (Caribbean 27\%, US 25\%) was similar in both popula- tions. The inability to achieve statistical significance for high-risk HPV infections may be related to the small sample size of the US population and consequently insufficient statistical power to detect a difference between the two groups. Nevertheless, our findings suggest that the higher rates of HPV infection in the Caribbean compared to the US, are likely to explain the higher incidence of cervical cancer reported in the region [2].

The distribution of HPV types was similar in the two Caribbean islands but was different from that observed in the US. This is not unexpected, since differences in the geographical distribution of HPV infections have previously been reported [9]. We observed that HPV 16 and 18 were not the predominant high-risk genotypes detected in cancer-free Caribbean women. Our results show that Caribbean women have a higher proportion of HPV 45 infections, the third most common high-risk HPV genotype that drives cervical carcinogenesis $[8,10]$. Studies are currently ongoing to determine whether HPV 45 infections might be driving cervical cancer development in the Caribbean region.

The current HPV vaccine prevents infections from HPV types $6,11,16$ and 18 [11]. The low-risk genotypes, HPV 6 and 11, are responsible for the development of genital warts, while HPV 16 and 18 are the two most common high-risk genotypes and are reported to account for almost $70 \%$ of cervical cancers worldwide [10]. We observed that HPV 16 and 18 infections are not seen in high proportions among cancer-free Caribbean women. However, Caribbean women still have a higher proportion of HPV 16 and 18 infections compared to their US counterparts (HPV 16: 13\% vs. 7\%, and HPV 18: $14 \%$ vs. $7 \%)$. These observed differences between the US and Car-

Table 3: Characteristics of HPV infections according to ethnicity.

Tobago N N (\%) Jamaica N (\%) US-Black N (\%) US-White N (\%) US-other N (\%) Total $\mathrm{N}(\%)$

Number of subjects
High-risk HPV infection
Low-risk HPV infection
Undetermined-risk infection
Single high-risk infection*
Multiple high-risk infection
Number of high-risk HPV types per subject
None**
I
2
3
4
5
6

212
$43(20.3)$
$15(7.1)$
$16(7.6)$
$49(23.1)$
$26(12.3)$
$169(79.7)$
$33(15.6)$
$7(3.3)$
$2(0.9)$
$1(0.5)$
$0(0.0)$
$0(0.0)$

99
$58(58.6)$
$25(25.3)$
$47(47.5)$
$40(40.4)$
$43(43.4)$
$41(41.4)$
$34(34.3)$
$11(11.1)$
$7(7.1)$
$2(2.0)$
$3(3.0)$
$1(1.0)$

10
$4(40.0)$
$4(40.0)$
$5(50.0)$
$5(50.0)$
$3(30.0)$
$6(60.0)$
$3(30.0)$
$1(10.0)$
$0(0.0)$
$0(0.0)$
$0(0.0)$
$0(0.0)$

67
$9(14.5)$
$4(6.5)$
$5(8.1)$
$10(16.1)$
$5(8.1)$
$53(85.5)$
$7(11.3)$
$2(3.2)$
$0(0.0)$
$0(0.0)$
$0(0.0)$
$0(0.0)$

$\begin{array}{cc}\text { II } & 393 \\ \text { I }(10.0) & I I 5(29.3) \\ \text { I }(10.0) & 49(12.5) \\ \text { I }(10.0) & 74(18.3) \\ \text { I }(10.0) & 105(26.7) \\ \text { I }(10.0) & 78(19.9) \\ & \\ 9(90.0) & 278(70.7) \\ \text { I }(10.0) & 78(19.9) \\ 0(0.0) & 2 I(5.3) \\ 0(0.0) & 9(2.3) \\ 0(0.0) & 3(0.8) \\ 0(0.0) & 3(0.8) \\ 0(0.0) & I(0.3)\end{array}$

*Includes subjects infected with low-risk and undetermined-risk HPV types; **Includes subjects that were HPV-negative or had only low-risk HPV infections. 
ibbean may be due to immune resistance to HPV16 and 18 genotypes in the US population (although we do not have data to support these hypotheses). The evaluation of serological status for HPV 16 and 18 and how these compare to the prevalence of high-risk HPV infections in both geographical regions are needed in order to test these hypotheses. Nevertheless, the higher incidence of cervical cancers in the Caribbean region compared to the US might be attributed to the higher proportions of HPV 16 and 18 infections observed in the Caribbean.

Caribbean and US-Black subjects in comparison with USWhites have higher prevalence rates of high-risk HPV infections and also a higher proportion of subjects with multiple-high-risk HPV infections. This may be related to sexual behaviour, social class (poverty and malnutrition), high parity, lack of barrier contraceptive protection and use of steroidal contraception, [7,12-16]. However, these confounders could not be assessed in our study because these data were not available. Furthermore, the risk of cervical cancer among women with multiple high-risk infections has not been well studied; therefore additional studies are warranted.

Studies show that younger age is associated with an increased risk of cervical HPV infection [17-20]. Therefore, for comparisons of HPV infections between different populations, age must be standardized. A limitation in our study is that although all subjects were recruited from the general population, the mean age for each country was different. Pittsburgh subjects were the oldest (mean age $=$ $53 \pm 9.0$ years), and this was representative of the older population in the geographical region [21]. Jamaican women were the youngest population, also reflecting the demographics for the country [22]. To address this limitation, we have presented age-adjusted prevalence rates so that these values might be compared. Another limitation in this study is that only $11 \%(\mathrm{~N}=10)$ of the US study population were African-American, which did not allow for adequate comparisons between African-American and Caribbean women. However, the proportion of AfricanAmerican subjects is representative of the Pittsburgh demographics.

\section{Conclusion}

The higher prevalence of cervical HPV infections and multiple high-risk infections in Caribbean and US-Black women may contribute to the high incidence and prevalence of cervical cancer in these populations. Further studies of the distribution of HPV types between ethnic groups and the risk of cervical cancer among women with multiple high-risk infections are currently ongoing.

\section{Competing interests}

The authors declare that they have no competing interests.

\section{Authors' contributions}

CR contributed to study design, sample/data collection for Tobago and US populations, performed the data analysis and wrote the manuscript. JBW performed the sample and data collection of the Tobago population. ET, contributed to the overall study design and the writing of the manuscript. AW, contributed to the study design, sample/ data collection of the Jamaican population and performed the HPV testing. NM and RE: contributed to study design of the US population. AP, V W, CB and SMG: contributed to study design and sample/data collection for the Tobago population. SE: performed the HPV testing. HF, DG, MJ, MS, NY, NMA: contributed to the study design, sample/ data collection of the Jamaican population. All co-authors reviewed and approved the manuscript.

\section{Acknowledgements}

This work is supported in part by NIH/R I 3 CA I 30596A, the UPCI Cancer Education and Career Development grant R25CA089507, and a GLMA foundation grant. This publication was also made possible by Grant Number KL2 RR024I54-03 to CCR, from the National Center for Research Resources (NCRR) [23], a component of the National Institutes of Health (NIH), and NIH Roadmap for Medical Research [24]. Its contents are solely the responsibility of the authors and do not necessarily represent the official view of NCRR or NIH. This publication was also supported by funds received from the NIH/NCRR GCRC Grant MOI-RR000056 and/or the CTSA Grant I UL I RR024I53-0I. The authors wish to thank the Tobago Branch of the Trinidad \& Tobago Cancer Society for providing the facilities for subject recruitment and sample collection for the Tobago subjects.

This article has been published as part of Infectious Agents and Cancer. Volume 4 Supplement I, 2009: Second Annual International African-Caribbean Cancer Consortium Conference. The full contents of the supplement are available online at http://www.infectagentscancer.com/4/supplements/4/SI.

\section{References}

I. Ries LAG, Melbert D, Krapcho M, Mariotto A, Miller BA, Feuer EJ, et al.: SEER Cancer Statistics Review, 1975-2004 National Cancer Institute. Bethesda, MD; 2007.

2. Ferlay J, Bray F, Pisani P, Parkin DM: GLOBOCAN 2002 Cancer Incidence, Mortality and Prevalence Worldwide IARC CancerBase, Version 2.0 No. 5. Lyon, IARC Press; 2004.

3. Steenbergen RD, de Wilde J, Wilting SM, Brink AA, Snijders PJ, Meijer C]: HPV-mediated transformation of the anogenital tract. J Clin Virol 2005, 32(SuppI I):S25-S33.

4. Kreimer AR, Clifford GM, Boyle P, Franceschi S: Human papillomavirus types in head and neck squamous cell carcinomas worldwide: a systematic review. Cancer Epidemiol Biomarkers Prev 2005, I 4:467-475.

5. Ragin CC, Kuo J, Taioli E: Prevalence of cancer-associated viruses in the Caribbean islands. Cancer Investigation 2008 in press.

6. Ragin CCR, Wheeler VW, Wilson JB, Bunker CH, Patrick AL, Gollin SM, et al.: Distinct distribution of HPV types among cancerfree Afro-Caribbean women from Tobago. Biomarkers 2007, 1 2:510-522.

7. Watt A, Garwood D, Jackson M, Younger N, Ragin C, Smikle M, et al.: High-risk and multiple human papillomavirus (HPV) infections in cancer-free Jamaican women. Infectious Agents and Cancer in press.

8. Munoz N, Bosch FX, de Sanjose S, Herrero R, Castellsague X, Shah $\mathrm{KV}$, et al.: Epidemiologic classification of human papillomavirus types associated with cervical cancer. N Engl J Med 2003, 348:518-527. 
9. Clifford GM, Gallus S, Herrero R, Munoz N, Snijders PJ, Vaccarella S, et al:: Worldwide distribution of human papillomavirus types in cytologically normal women in the International Agency for Research on Cancer HPV prevalence surveys: a pooled analysis. Lancet 2005, 366:991-998.

10. Munoz N, Bosch FX, Castellsague X, Diaz M, de Sanjose S, Hammouda $D$, et al.: Against which human papillomavirus types shall we vaccinate and screen? The international perspective. Int J Cancer 2004, I I I :278-285.

II. FDA Licenses New Vaccine for Prevention of Cervical Cancer and Other Diseases in Females Caused by Human Papillomavirus, Food \& Drug Administration [http://www.fda.gov/ bbs/topics/NEWS/2006/NEWO1385.html]

12. Fletcher HM, Hanchard B: Poverty eradication and decreased human papilloma virus related cancer of the penis and vulva in Jamaica. J Obstet Gynaecol 2008, 28:333-335.

13. Kahn JA, Lan D, Kahn RS: Sociodemographic Factors Associated With High-Risk Human Papillomavirus Infection. Obstet Gynecol 2007, I 1 0:87-95.

14. de Sanjose S, Bosch FX, Munoz N, Shah K: Social differences in sexual behaviour and cervical cancer. IARC Sci Publ; 1997:309-317.

15. McFarlane-Anderson N, Bazuaye PE, Jackson MD, Smikle M, Fletcher HM: Cervical dysplasia and cancer and the use of hormonal contraceptives in Jamaican women. BMC Womens Health 2008, 8:9.

16. Bazuaye PE, Fletcher H, McFarlane-Anderson N: Lifestyle and cervical dysplasia in Jamaica. Int J Gynaecol Obstet 2004, 84: I75- I 77.

17. Kjaer SK, Breugelmans G, Munk C, Junge J, Watson M, Iftner T: Population-based prevalence, type- and age-specific distribution of HPV in women before introduction of an HPV-vaccination program in Denmark. Int J Cancer 2008, I 23: I 864-I870.

18. Kitchener HC, Almonte M, Wheeler P, Desai M, Gilham C, Bailey A, et al: HPV testing in routine cervical screening: cross sectional data from the ARTISTIC trial. $\mathrm{Br} J$ Cancer 2006, 95:56-6I.

19. Dunne EF, Unger ER, Sternberg M, McQuillan G, Swan DC, Patel SS, et al: Prevalence of HPV infection among females in the United States. JAMA 2007, 297:8I3-8I9.

20. Herrero R, Castle PE, Schiffman M, Bratti MC, Hildesheim A, Morales J, et al:: Epidemiologic profile of type-specific human papillomavirus infection and cervical neoplasia in Guanacaste, Costa Rica. J Infect Dis 2005, 191: 1796-1807.

21. Pennsylvania Department of Health Annual Report of Vital Statistics, Pennsylvania Vital Statistics 2006 [http:/l] www.dsf.health.state.pa.us/health/cwp/view.asp? $a=175 \& q=250106$

22. U.S.Census Bureau, Population Division/International Programs Center, International Database Summary Demographic Data [http://www.census.gov/ipc/www/idb/]

23. National Institutes of Health, National Institutes of Health, National Center for Research Resources [http:// www.ncrr.nih.gov/]

24. NIH Roadmap for Medical Research, NIH Roadmap for Medical Research, Re-engineering the Clinical Research Enterprise [http://nihroadmap.nih.gov/clinicalresearch/overviewtranslational.asp]

Publish with Bio Med Central and every scientist can read your work free of charge

"BioMed Central will be the most significant development for disseminating the results of biomedical research in our lifetime. "

Sir Paul Nurse, Cancer Research UK

Your research papers will be:

- available free of charge to the entire biomedical community

- peer reviewed and published immediately upon acceptance

- cited in PubMed and archived on PubMed Central

- yours - you keep the copyright

Submit your manuscript here:

http://www.biomedcentral.com/info/publishing_adv.asp
BioMedcentral 